IV Concurso Integrado de Desenvolvimento de Soluções de Tecnologia e Objetos de Aprendizagem

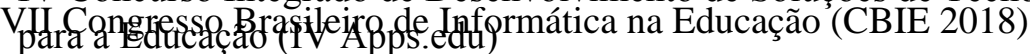

Anais dos Workshops do VII Congresso Brasileiro de Informática na Educação (WCBIE 2018)

\title{
Utilizando mecânicas de jogo para dinamizar o aprendizado da língua Esperanto
}

\author{
Manoela Fernandes Vieira Barbosa, Bárbara de Sousa Ramos, Hyuan Peixoto Farrapo, \\ Lívia Rodrigues Cavalcante de Oliveira, Lucas Weiby Sousa de Lima, Caio Ramon \\ Gomes de Freitas, Ma. de Fátima Costa de Souza, Cátia Luzia Oliveira da Silva, Ma. \\ Joelma Pereira Peixoto, Vanessa Ester Silva Farias
}

\author{
Instituto UFC Virtual - Sistemas e Mídias Digitais - Universidade Federal do Ceará (UFC) - \\ Caixa Postal 60440-554 - Fortaleza - CE - Brasil \\ \{manoelafvb, liviarco, lucas_weiby\}@alu.ufc.br, \{barbinhasramos, \\ hyuanpeixoto, caioramon62014,jlmpxt\} egmail.com \\ \{catia, fatimasouza, ester\} @virtual.ufc.br
}

\begin{abstract}
Resumo. São vários os motivos que levam as pessoas aprenderem um idioma, mas no geral, a busca por uma aproximação com outros povos, costumes e nações guiam a intencionalidade do maior número de pessoas. No sentido de estabelecer e elevar essa aproximação, o presente artigo apresenta o software "Lerni", recurso educacional digital em formato aberto que utiliza mecânicas de jogo, com o objetivo principal de auxiliar no aprendizado da língua Esperanto. A proposta de "Lerni" é servir de elemento mediador entre professores e alunos de cursos livres de Esperanto ou de Educação Básica, colaborando assim, com a formação de conhecimentos e valores definidos na atual Base Nacional Comum Curricular brasileira.
\end{abstract}

\section{Cenário de uso}

O Esperanto é uma língua planejada, criada pelo médico russo-polonês Luís Lázaro Zamenhof, cujo livro, lançado em 1887, apresentou a funcionalidade linguística de sua gramática básica. Popularizou-se por ter a filosofia de se tornar uma língua que une povos e diminui as barreiras linguísticas, tendo falantes em 120 países, membros da Universala Esperanto-Asocio (UEA - Associação Universal de Esperanto).

Hoje, apesar de ter inúmeras entidades que se comunicam em Esperanto, não existe para a língua portuguesa, até o momento, um curso ou plataforma de auxílio ao ensino de Esperanto voltado especialmente para crianças e adolescentes de forma digital e dinâmica que desperte interesse por essa língua, sua história e filosofia. Por este motivo, a proposta apresentada nesse artigo visa envolver maneiras de difundir a língua de modo que mais pessoas possam aderir ao seu uso.

O protótipo do recurso educacional digital (RED) "Lerni” foi criado com o objetivo de auxiliar docentes de Esperanto no ensino da língua para crianças, já alfabetizadas na língua portuguesa, com idade entre 8 a 12 anos, correspondendo, portanto, à faixa etária atendida nos anos iniciais do Ensino Fundamental.

Esse recurso educacional digital pode ser aplicado em Desktop nos laboratórios de informática de escolas e também em aparelhos celulares, com acesso à Internet, através dos principais navegadores, como Mozilla Firefox, Google Chrome, Opera, Safari e Microsoft 
IV Concurso Integrado de Desenvolvimento de Soluções de Tecnologia e Objetos de Aprendizagem

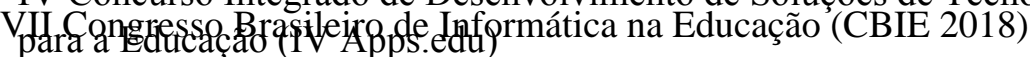

Anais dos Workshops do VII Congresso Brasileiro de Informática na Educação (WCBIE 2018)

Edge. Tem design responsivo e não requer instalação. Ainda que desenvolvido para ser um complemento a aulas presenciais de cursos de Esperanto, seu caráter independente possibilita a diversidade de perfil de usuários, pois pode ser usado como revisão e entretenimento para falantes da língua, independente da idade, que se interessam por softwares do gênero.

Além disso, a didática aplicada no desenvolvimento do conteúdo foi selecionada para estimular o desejo da aprendizagem dessa língua universal pelas novas gerações, pois dentro da proposta da língua há também o ganho pedagógico do recurso: utilizar-se de elementos de ludificação em seu ensino e prática, mantendo viva uma língua criada na perspectiva da inclusão de diferentes povos, portanto, uma língua que respeita a diversidade, além de ser uma alternativa a línguas populares como Inglês e Mandarim.

\section{Desenvolvimento}

O RED "Lerni” foi criado a partir do apoio da Associação Cearense de Esperanto (ACE) e do Instituto Virtual da Universidade Federal do Ceará (UFC), dentro da disciplina de Projeto Integrado I, para o curso de Bacharelado em Sistemas e Mídias Digitais da turma do primeiro semestre de 2018. O processo de desenvolvimento foi dividido em: adaptação de conteúdo da língua para a narrativa e mini jogos, criação da narrativa, design de personagens e cenários, arquitetura da informação, game design e design da interface gráfica, além da implementação.

A adaptação do conteúdo de vocabulário foi feita com o apoio de dois docentes, sendo um deles membro da ACE e o outro, professor de Educação Básica, que foram responsáveis pela escolha, definição e estruturação do conteúdo abordado no RED.

A partir dessa etapa, iniciou-se a criação da narrativa que ambienta os mini jogos, por meio da plataforma de edição de texto online (Documentos do Google). O design de personagens e cenário veio em sequência, onde se fez uso da ferramenta Adobe Illustrator CC, disponibilizada em laboratórios de informática pelo Instituto Virtual da UFC, para todas as ilustrações e elementos visuais do projeto. A arquitetura da informação, junto ao game design e ao design da interface gráfica, foram adaptados ao longo do processo de criação, entre protótipos de baixa fidelidade em papel, até a versão beta. Estes processos também se utilizaram da ferramenta Adobe Illustrator CC em suas fases finais.

As ilustrações foram inspiradas no estilo Flat 2.0 e as referências utilizadas para o game design foram jogos para dispositivos móveis que são populares com a faixa-etária em questão, como "Cut the Rope ${ }^{\mathrm{TM}}$ ", da Chillingo'. Para o design de personagens, as referências foram da franquia "Keroppi", da Sanrio Co., Ltd, da animação japonesa "Sargento Keroro" de Mine Yoshizaki, e da animação "As Meninas Superpoderosas", de Craig McCracken, exibidas pelo canal de televisão Cartoon Network.

Baseamos nossas três cores de interface numa paleta sugerida por Heller (2000), que transmite sensações de esperança. Adaptamos sua saturação, no entanto, para assemelhar-se a paleta de cores presentes em outras mídias que seguem o estilo de Flat 2.0.

\footnotetext{
${ }^{1}$ Disponível em: <https://play.google.com/store/apps/details?id=com.zeptolab.ctr.ads\&hl=pt_BR>
} 
IV Concurso Integrado de Desenvolvimento de Soluções de Tecnologia e Objetos de Aprendizagem

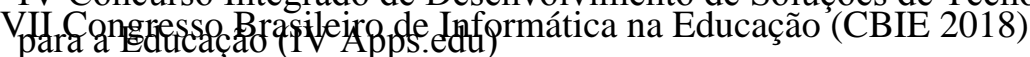

Anais dos Workshops do VII Congresso Brasileiro de Informática na Educação (WCBIE 2018)

A implementação foi feita após a definição básica do design da interface gráfica. Para esta etapa, fez-se uso do framework de JavaScript de código aberto, Phaser, na versão 2.10.5 $\mathrm{CE}$, criado especificamente para o desenvolvimento de jogos. A escolha desta versão se deu pelo fato da documentação atual ser mais abrangente e mais estável, uma vez que, no Phaser 3 , algumas funções ainda estão sendo migradas. Durante o processo de desenvolvimento do protótipo foram feitas diversas otimizações, como downgrade da qualidade das artes, compactação de elementos que realizam a mesma função para um formato de spritesheet, otimização do código e de melhores possibilidades de utilizar a ferramenta de maneira mais leve (como mudar a maneira de renderização, para uma mais amplamente suportada: WebGL para Canvas), até chegar ao código final atualmente utilizado.

A narrativa gira em torno do personagem principal, o sapo Floppy, e seus amigos, o sapo Lolô e o crocodilo Jiló, que se unem para aprender a língua do Esperanto enquanto exploram a cidade com a missão de fazer uma festa de recepção para a família de Floppy, que virá de várias partes do mundo, porém se comunicarão por meio de Esperanto, que Floppy ainda não domina.

O projeto foi estruturado em 6 arquivos principais: O primeiro é apenas o HTML responsável por executar o JavaScript. O segundo é responsável por carregar todos os arquivos necessários para o jogo: esquema de navegação do RED e algumas funções gerais, como atualização de valores, randomização, etc. Os outros 4 são os arquivos contendo, em cada um, um mini jogo e suas mecânicas, regras e modo de utilização das artes.

As artes presentes no jogo são utilizadas em forma de plano de fundo, de caráter decorativo, e spritesheets dinâmicos em formato JSON, que compõem os objetos interativos do jogo e a maioria dos botões da interface.

Durante o processo de desenvolvimento, para as otimizações, foram feitos testes em dispositivos móveis, que utilizam o sistema operacional Android, e computadores pessoais de sistema operacional Windows 10 e Linux, de maneira a identificar possíveis erros e melhorias de desempenho. O protótipo foi executado em um servidor local, utilizando para isso ferramentas que se integram ao Apache, como o Xampp, para simular uma conexão com a Internet, e executá-lo a partir de navegadores.

Ao final dos testes das mecânicas pelos desenvolvedores, foi realizado a validação do RED com um grupo de 7 crianças com idade entre 7 e 12 anos do bairro Passaré, em Fortaleza - CE, que nunca tiveram contato com a língua Esperanto, utilizando-se de um computador com sistema operacional Windows 10 , com acesso à Internet, por meio do navegador Mozilla Firefox. O objetivo da avaliação foi testar a navegação entre as telas e menus, o apelo visual do recurso e a clareza das funcionalidades dos botões, além das mecânicas dos mini-jogos.

A avaliação contou com dois dos desenvolvedores presentes, que acompanharam e observaram as ações dos participantes ao interagir com o RED e anotaram suas dificuldades. Após o teste, foi feito um questionário com 3 perguntas referentes às opiniões dos participantes quanto ao RED, nas quais eles as responderam por meio de um carômetro, que consistia em caricaturas expressivas representando emoções de tristeza, indiferença, confusão e alegria. As perguntas foram em relação ao contato anterior dos participantes com o Esperanto, se havia ou não; se o contato com o RED os havia motivado a aprender Esperanto 
IV Concurso Integrado de Desenvolvimento de Soluções de Tecnologia e Objetos de Aprendizagem

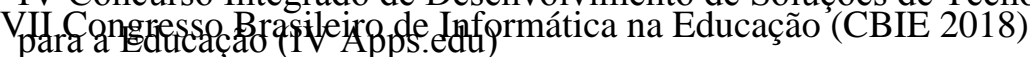

Anais dos Workshops do VII Congresso Brasileiro de Informática na Educação (WCBIE 2018)

e se eles teriam interesse em outros recursos digitais semelhantes. Estes métodos de questionário e teste foram utilizados levando em consideração a idade dos participantes e as técnicas de avaliação de Interação Humano-Computador, em especial a de observação (BARBOSA e SILVA, 2010). A partir desse teste constatou-se a necessidade de um redesign das cores previamente escolhidas para alguns elementos de interface, além da inserção de botões de navegação para se voltar para telas anteriores.

Por fim, os desenvolvedores decidiram por categorizar o RED dentro da licença de Creative Commons, Atribuição-NãoComercial-CompartilhaIgual CC BY-NC-SA, para que seja possível o aprimoramento do projeto por aqueles que tiverem o interesse, principalmente para professores da área de Esperanto, de modo que facilite a disseminação do recurso entre a comunidade Esperantista.

\section{Apresentação do software}

O RED Lerni conta com uma interação de navegação, em que, através de botões, o usuário pode acessar as diversas telas disponíveis. Ao iniciar o sistema, o usuário irá visualizar a tela de menu que contém os seguintes botões no canto inferior central da tela, identificados da esquerda para a direita de acordo com a figura 1 e 2 : créditos (1), jogar (2) e configurações (3), representados por ícones.

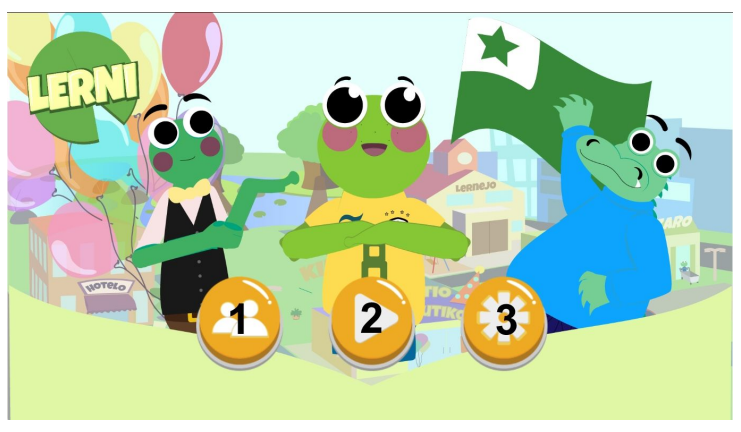

Figura 1 - Menu inicial. Fonte: Própria (2018)

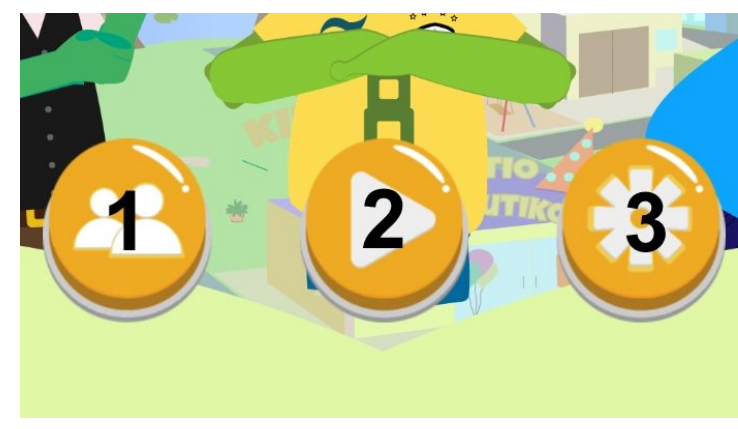

Figura 2 - Botões do menu inicial em evidência. Fonte: Própria (2018)

Ao selecionar um dos botões o jogador deve ser redirecionado para a sua respectiva tela. Sua navegação é semelhante a uma navegação padrão de jogos para dispositivos móveis, com menus em tela cheia e menus em pop-up, que são acessados por meio de cliques em seus respectivos botões.

Selecionando o botão jogar (indicado pelo número 1, nas Figuras 1 e 2), inicia-se a apresentação da narrativa inicial do jogo (Figura 3), no estilo visual novel, em que os diálogos aparecem em caixas de texto no canto inferior da tela (4), e, no plano de fundo (5), ilustrações dos personagens simulam as cenas. Seu conteúdo apresenta o contexto do jogo e a língua Esperanto. Estão disponíveis botões (figura 3 e 4) que permitem ao usuário voltar (6) ou avançar (7) na história, por meio de setas para esquerda ou direita, bem como a opção de ignorar toda a narrativa e ser direcionado ao menu de níveis (8). O usuário também conta com um menu retrátil (9), representado por um ícone de adição, no canto superior esquerdo, que contém botões com atalhos para as seguintes telas (Figura 4): tela inicial (10), menu de níveis 
IV Concurso Integrado de Desenvolvimento de Soluções de Tecnologia e Objetos de Aprendizagem

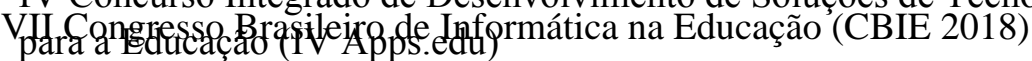

Anais dos Workshops do VII Congresso Brasileiro de Informática na Educação (WCBIE 2018)

(11), menu pop-up de ajuda (12) e menu pop-up de configuração (13). O menu retrátil está presente em todas as telas, exceto no menu inicial.

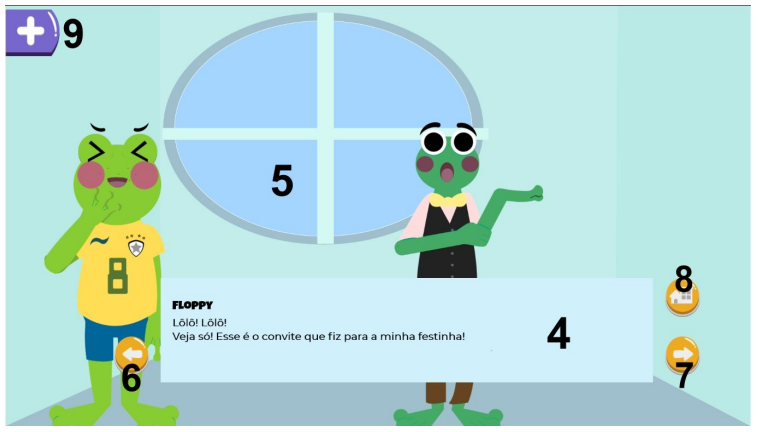

Figura 3 - Tela de narrativa inicial. Fonte: Própria (2018)

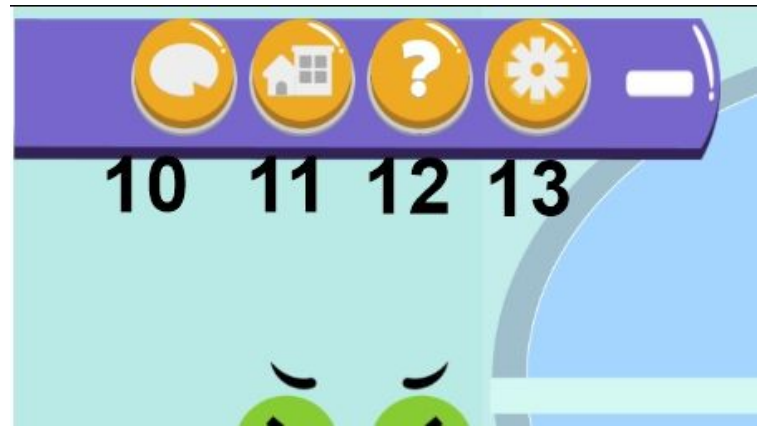

Figura 4 - Menu retrátil aberto com botões em evidência. Fonte: Própria (2018).

Ao passar da narrativa inicial, o sistema levará o usuário para a tela do menu de níveis (Figura 5). Trata-se da tela que contém as fases e módulos a serem jogados, sendo cada fase representada por um elemento de uma cidade relacionado ao assunto proposto. Cada elemento da cidade (prédios ou casas) funciona como botão para acessá-los.

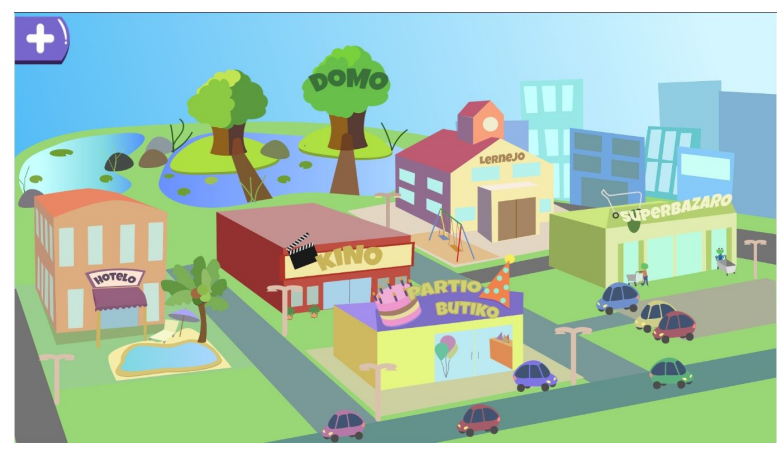

Figura 5 - menu de níveis. Fonte: Própria (2018).

Selecionada a fase, haverá o redirecionamento à tela de módulos (figuras 6 e 7), que possui os tópicos disponíveis daquele nível, indicados por números, para a ordem de acesso. Os botões numerados estão mesclados em elementos do cenário.

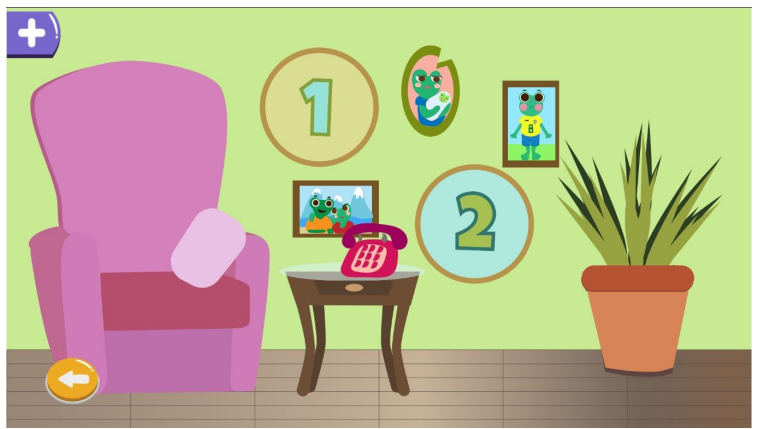

Figura 6 - Tela de módulos 1. Fonte: Própria (2018)

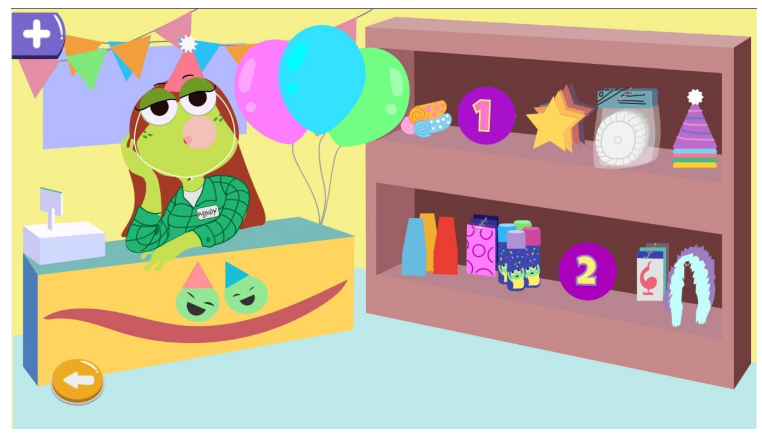

Figura 7 - Tela de módulos 2. Fonte: Própria (2018) 
IV Concurso Integrado de Desenvolvimento de Soluções de Tecnologia e Objetos de Aprendizagem

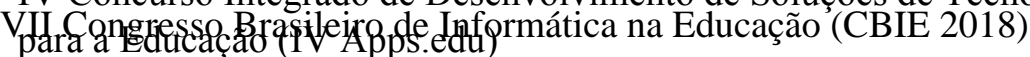

Anais dos Workshops do VII Congresso Brasileiro de Informática na Educação (WCBIE 2018)

Escolhido o módulo, o usuário será introduzido a uma nova tela de narrativa (figura 8), que contextualiza o conteúdo proposto pelo módulo. Acima do botão de avançar na narrativa há um botão que avança direto para as instruções (figura 9), que contém as diretrizes do mini jogo proposto. Esta tela conta com um botão para fechar (15), que o fará avançar para o mini jogo.

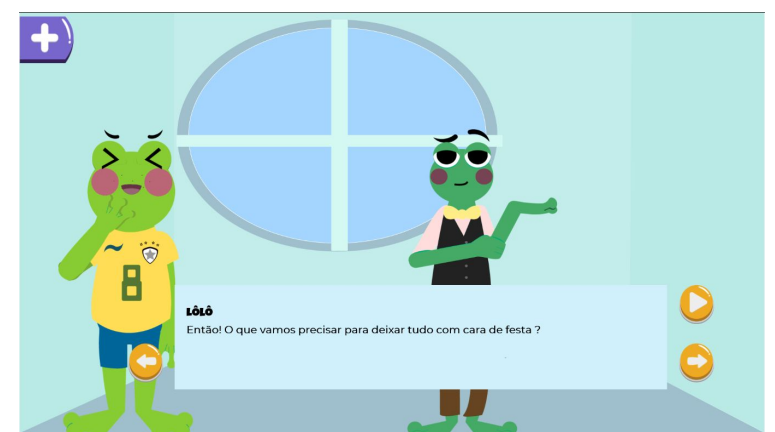

Figura 8 - Narrativa do módulo 1. Fonte: Própria (2018)

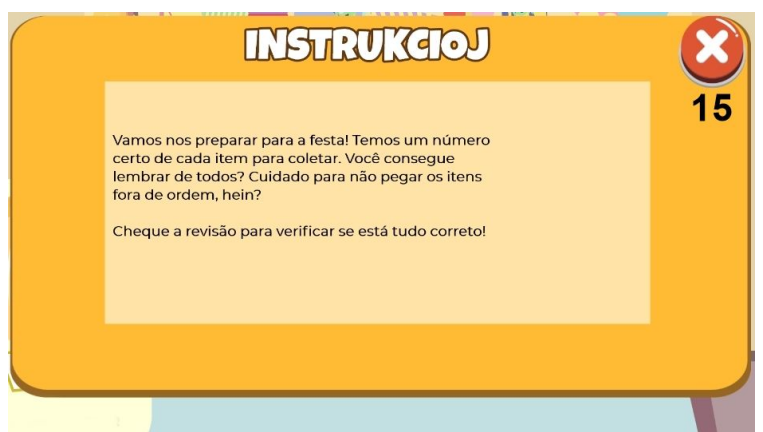

Figura 9 - Pop up de instruções. Fonte: Própria (2018)

Passadas as instruções haverá uma mudança de tela para o mini jogo interativo (Figura 11). Nela há um botão que permite o usuário pausar o jogo (16), além do botão de pop-up de revisão (17) (em evidência na figura 10) do conteúdo, ambos presentes no canto superior direito. Na tela também se fazem presentes, nos cantos superiores centrais, a informação sobre o tempo decorrido durante o mini jogo e/ou pontuação do jogador (18). Ao final do mini jogo, o usuário é introduzido a uma tela de conclusão da fase (figura 12), na qual o sistema revelará o desempenho do jogador, representado por estrelas. $\mathrm{O}$ usuário poderá jogar novamente selecionando o botão assim rotulado (19) ou retornar à tela de módulos a partir do botão de avançar (20), representado pela seta para a direita.

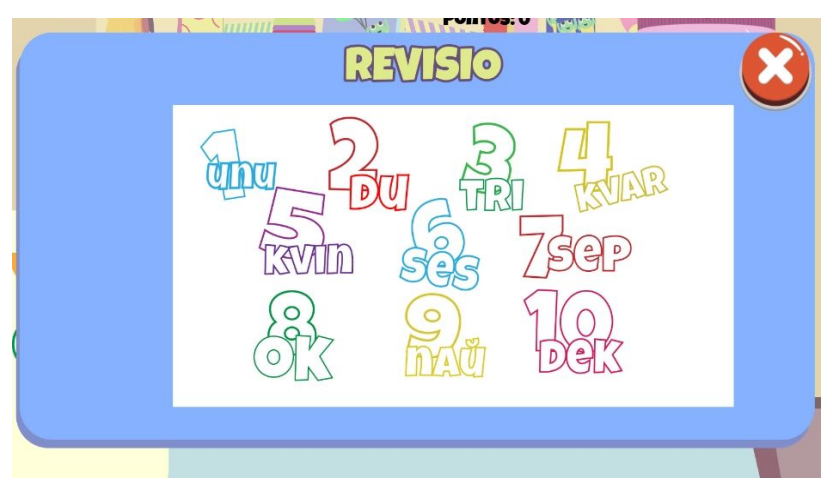

Figura 10 - Pop-up de revisão. Fonte: Própria (2018). 
IV Concurso Integrado de Desenvolvimento de Soluções de Tecnologia e Objetos de Aprendizagem

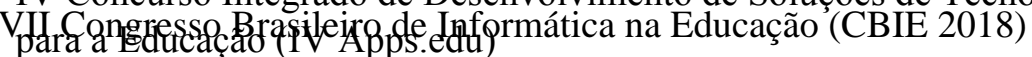

Anais dos Workshops do VII Congresso Brasileiro de Informática na Educação (WCBIE 2018)

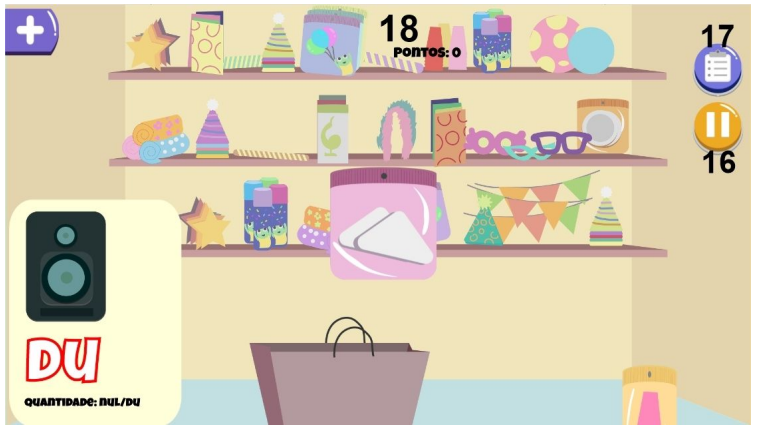

Figura 11 - Tela de mini jogo. Fonte: Própria (2018)

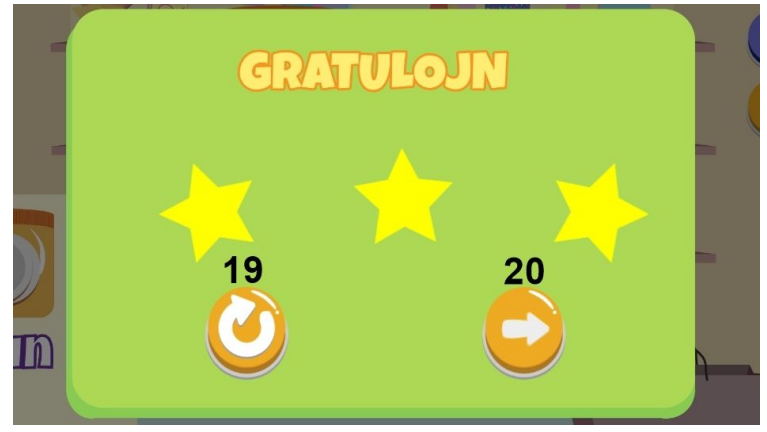

Figura 12 - Tela de congratulações ao fim do jogo. Fonte: Própria (2018).

Escolhendo o botão de pop-up de ajuda no menu retrátil (Figura 13), será possível visualizar as informações acerca da própria navegação do sistema através de botões para avançar ou voltar, representados por setas. Todos os pop-ups do jogo tem a opção de serem fechados por meio do ícone de "fechar", representado por um botão com um "x", no canto superior direito da janela do pop-up. $\mathrm{O}$ menu de configurações, ao ser acessado pelo menu retrátil, apresenta somente a opção inativa de modificação de som. Ao ser acessado pelo menu principal (Figura 14), no entanto, há a opção de alterar o tamanho da fonte (21).

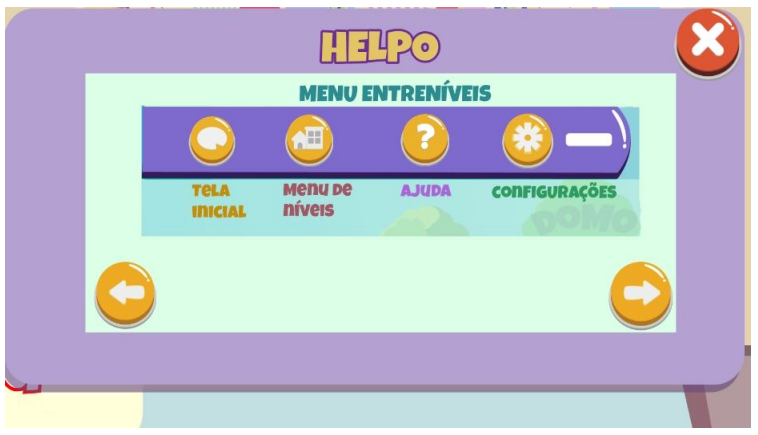

Figura 13 - Menu pop up de ajuda. Fonte: Própria (2018).

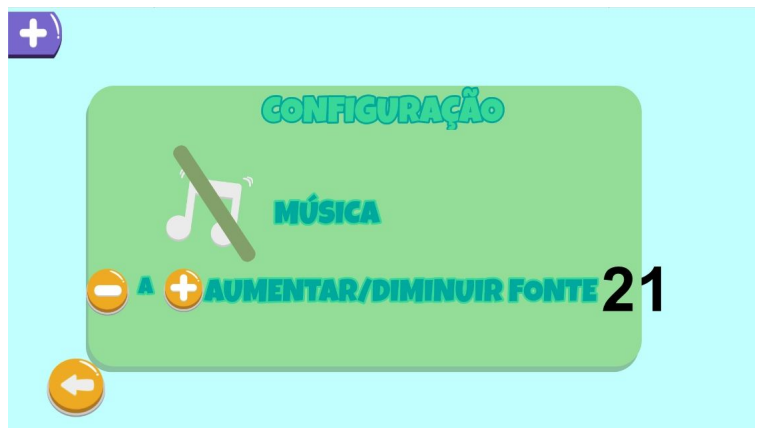

Figura 14 Menu de configuração acessado pelo menu principal. Fonte: Própria (2018).

O protótipo pode ser acessado em https://lerniesperanto.github.io

\section{Considerações finais}

"Lerni" foi desenvolvido para a disciplina de Projeto Integrado 1, do curso de bacharelado em Sistemas e Mídias Digitais, da Universidade Federal do Ceará, com o apoio da ACE. Como apresentado anteriormente, o objetivo deste protótipo consiste em auxiliar docentes no ensino da Língua Esperanto. Nesse sentido, 3 professores membros da ACE foram os usuários que, a princípio, fizeram uso do recurso "Lerni". Os referidos docentes são responsáveis por uma turma na Escola de Primeiro Grau Santa Terezinha, em Ponta da Serra - Itaitinga, no estado do Ceará, e queriam tornar estimulante o estudo da língua para seus alunos, devido sua importância ao caráter inclusivo, de se tornar acessível a todos. 
IV Concurso Integrado de Desenvolvimento de Soluções de Tecnologia e Objetos de Aprendizagem

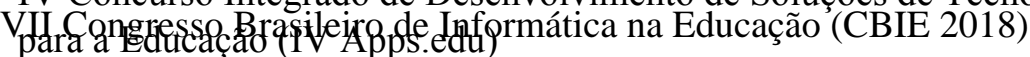

Anais dos Workshops do VII Congresso Brasileiro de Informática na Educação (WCBIE 2018)

A equipe de desenvolvedores planeja aperfeiçoar o RED de modo que ele atenda às necessidades da ACE, tenha melhores bases pedagógicas em suas interações com o usuário e possa, posteriormente, ser um curso completo, adaptado completamente para o Esperanto, de modo que seja referência para o aprendizado da língua para crianças em todo o mundo. Além disso, disponibilizar o software em formato aberto, de modo a possibilitar o uso adaptado e criativo de seu conteúdo por professores ou mesmo por estudantes da área de tecnologia educacional ou por crianças e jovens empreendedores, curiosos e desejosos de criar seu próprio método de aprendizagem.

Como próximos passos, planeja-se incluir aspectos de acessibilidade no RED e criar mais níveis interativos. A meta será possibilitar a ativação de ferramentas de acessibilidade no pop-up de configurações, no qual terão botões que modificam os elementos do RED, que consistirão em poder retirar a música ou os efeitos sonoros do sistema, leitor de tela e alteração do tamanho da fonte padrão para outra predefinição. Os outros níveis a serem incluídos irão abranger os básicos de fonética, grafia, morfologia e sintaxe da língua. Dessa maneira "Lerni" poderá ser um curso completo para iniciantes interessados em Esperanto.

\section{References}

Amery, H. (2004) "Mil Unuaj Vortoj En Esperanto”.

Barbosa, S.D.J.; Silva, B.S. da. (2010) "Interação humano-computador." Elsevier: Rio de Janeiro.

Creative Commons, (2018). "Attribution-NonCommercial-ShareAlike 4.0 International (CC BY-NC-SA 4.0)" disponível em: <https://creativecommons.org/licenses/by-nc-sa/4.0/>, acesso em: 30 Jun. 2018.

Heller, E. (2014) “A Psicologia das Cores: como as cores afetam a emoção e a razão.” Gili: São Paulo. $1^{\text {a }}$ Edição.

JSON, (2018) "Introdução ao JSON", disponível em <https://www.json.org/json-pt.html>, acesso em: 30 Jun. 2018.

Ministério da Educação. (2017) "Base Nacional Comum Curricular”. Brasília

Krug, S. (2008) "Não me faça pensar!” Alta Books: Rio de Janeiro. 2a Edição

Phaser, (2018). "Phaser 2.6.2 API Docs - Learn - Phaser", disponível em: $<$ https://phaser.io/docs/2.6.2/index>, acesso em: 30 Jun. 2018.

Schlatter, T; Levinson, D. (2013) "Visual Usability: principles and practices for designing digital applications." Elsevier: Waltham. 